\title{
Os financiamentos do BNDES e a inserção das firmas no comércio internacional: uma análise a partir de microdados ${ }^{\dagger}$
}

\author{
Carlos Eduardo Lobo e Silva*
}

\begin{abstract}
RESUMO - Este trabalho investiga, através da utilização do Propensity Score Matching, se os programas de financiamento do Banco Nacional do Desenvolvimento (BNDES) - não diretamente relacionados à exportação - contribuem para a inserção de novas firmas na base exportadora brasileira. O artigo utiliza dados de 1996 a 2006, oriundos da integração desenvolvida pelo Instituto de Pesquisa Econômica Aplicada (IPEA) de diversas bases de dados que contêm informações por firma. Os resultados do artigo mostram que para todos os anos analisados, a probabilidade de uma empresa financiada pelo BNDES iniciar atividade de exportação em um dos três anos subsequentes ao financiamento é maior que a probabilidade das empresas não financiadas ingressarem neste mercado e as diferenças são estatisticamente significativas a $5 \%$.
\end{abstract}

Palavras-chave: Financiamento do BNDES. Exportação. Propensity score matching.

\section{INTRODUÇÃO}

O debate sobre o papel do BNDES na promoção do desenvolvimento econômico do país não se restringe à esfera acadêmica; ao contrário, políticos, empresários e jornalistas discutem a questão e, dado o caráter intervencionista que as atividades do banco exigem, frequentemente os argumentos não vão muito além das visões ideológicas de cada parte sobre os caminhos para o desenvolvimento da economia.

Se o consenso parece distante, há um aspecto que tem unido correntes políticas distintas que comandaram o BNDES nos últimos anos: os desembolsos dirigidos para a promoção do comércio exterior - e principalmente das exportações - vem crescendo significativamente nos últimos anos. Portanto, a competitividade internacional das nossas empresas parece ser uma questão de importância crescente para os gestores das políticas públicas no país.

O que se pretende nesse trabalho é avaliar os efeitos das atividades do BNDES na capacidade das empresas brasileiras de entrar no comércio internacional. Os testes procuram

\footnotetext{
† Os resultados deste trabalho fazem parte de uma pesquisa coordenada pelo IPEA.

* Doutor em Planejamento Regional e Urbano pela University of Illinois at Urbana-Champaign (UIUC). Professor adjunto do Departamento de Economia da Pontifícia Universidade Católica do Rio Grande do Sul (PUC-RS). Endereço eletrônico: carlos.silva@pucrs.br.
} 
identificar se os programas do banco de desenvolvimento - não diretamente relacionados à exportação - contribuem para a inserção de novas firmas na base exportadora brasileira.

Sobre a política de promoção das exportações brasileiras, Markwald e Puga (2002) mostram em estudo detalhado que a base exportadora do Brasil não é tão pequena quanto o percentual das empresas que exportam em relação ao total (0,8\% das empresas em 2000) pode sugerir e que, excluindo-se as empresas voltadas à produção de nontradeables e/ou as microempresas ( $93 \%$ do universo das empresas), percebe-se que 40,6\% das empresas de porte médio e 86,5\% das grandes empresas exportam. Por outro lado, Araújo e De Negri (2006) citam a literatura internacional para lembrar que muitos apontam dificuldades na tarefa de inserir novas empresas na base exportadora do país; tarefa necessária, segundo os autores, uma vez que o aumento das exportações brasileiras exige a ampliação da base exportadora, pois são limitados os ganhos advindos apenas do crescimento dos coeficientes de exportação das firmas já inseridas no mercado internacional.

Vale dizer que o que se pretende testar é o efeito indireto dos financiamentos do BNDES na base de exportação brasileira. Diversos trabalhos empíricos mostram, por exemplo, que as empresas maiores e mais produtivas $^{1}$ têm maior probabilidade de iniciar atividades exportadoras. Além disso, o efeito dos financiamentos do BNDES na produtividade das empresas parece ser positivo $^{2}$. Portanto, o fato da empresa obter o financiamento do BNDES não afeta, necessariamente, de maneira direta sua capacidade exportadora. A entrada da empresa financiada pelo banco no mercado internacional sugere que o apoio do BNDES fortalece uma ou mais características importantes para se iniciar as exportações, porém a determinação de quais são essas características foge do escopo do presente trabalho.

O presente trabalho está dividido em quatro seções, incluindo esta introdução. A seção 2 traz a metodologia empregada. A seção 3 apresenta os resultados obtidos pelos modelos propostos e a seção 4 fecha o artigo com as conclusões do trabalho.

\section{METODOLOGIA}

Evidentemente, quando se opta pela análise dos efeitos de determinada política através da comparação entre dois grupos, sendo um deles de controle, deve-se levar em conta que estes grupos podem apresentar características distintas, além do fato de terem sido ou não

\footnotetext{
1 Veja, por exemplo, De Negri (2003) e Araújo (2006).

${ }^{2}$ Veja Souza e Ottaviano (2008).
} 
objeto da política em questão. No caso da avaliação dos programas do BNDES, a simples comparação entre (1) o percentual das empresas que entraram no mercado internacional e não receberam apoio do BNDES e (2) o percentual de empresas que entraram no mercado internacional e que receberam apoio do BNDES não seria uma estratégia precisa. Isto porque as empresas que recebem o financiamento do banco de desenvolvimento podem ser, por exemplo, empresas maiores, e dado que a literatura nos mostra que o tamanho da firma está relacionado com o sucesso no mercado internacional, o tamanho das empresas afetaria duas variáveis independentes, entre elas: financiamento e probabilidade de inserção no mercado internacional.

Para se criar grupos de controle apropriados e alcançar os objetivos expostos acima, este trabalho utilizou a técnica do Propensity Score Matching (PSM), seguindo o algoritmo proposto por Parsons (2001). Como salientado por Araújo (2006), uma das vantagens da técnica é a simplicidade computacional, especialmente importante quando se lida com amostras compostas por milhares de observações.

Os dados utilizados no trabalho vêm da integração desenvolvida pelo Instituto de Pesquisa Econômica Aplicada (IPEA) de diversas bases que contêm informações por firma. A maior parte das variáveis é oriunda da Pesquisa Industrial Anual (PIA) do Instituto Brasileiro de Geografia e Estatística (IBGE). A Relação Anual de Informações Sociais (RAIS) do Ministério do Trabalho e Emprego (MTE) forneceu dados sobre escolaridade média dos trabalhadores e o tempo de serviço do funcionário mais antigo, usado aqui como uma proxy para a idade da empresa. As informações sobre exportação vieram da base de dados da Secretaria do Comércio Exterior (Secex) do Ministério do Desenvolvimento, Indústria e Comércio (MDIC).

O procedimento utilizado na avaliação dos programas de financiamento do BNDES considera as firmas domésticas e inicia com um modelo Probit em que a variável dependente binária corresponde ao fato da empresa ter ou não ter recebido algum financiamento do banco. Definidas as variáveis independentes, cuja escolha será detalhada mais adiante, o PSM casa as empresas que receberam o financiamento com aquelas de características similares que não o receberam. Este casamento é feito através da probabilidade definida no modelo Probit. Numa primeira etapa, o algoritmo encontra empresas não financiadas, cujas probabilidades são idênticas às probabilidades das empresas financiadas até a sexta casa decimal. Os pares formados são separados da amostra e novos casamentos são definidos para as restantes, agora unindo empresas financiadas e não financiadas com probabilidades coincidentes até a quinta 
casa decimal e assim sucessivamente até a segunda casa decimal. Como resultado, teremos quatro grupos: (1) x empresas não financiadas que não foram casadas; (2) y empresas não financiadas casadas; (3) y empresas financiadas casadas e (4) z empresas financiadas não casadas.

A determinação das variáveis independentes do modelo obedeceu ao seguinte critério: em um primeiro momento, escolheram-se (1) as variáveis que a literatura aponta como importantes para a exportação das firmas e (2) a forma funcional do modelo. No caso do ajuste ser insatisfatório, pequenas modificações, como alterações funcionais e exclusão de variáveis originais, foram experimentadas, preservando-se as mais importantes conforme os trabalhos empíricos da área, tal como produtividade e tamanho da firma.

O critério adotado e as variáveis independentes utilizadas no modelo foram os seguintes: (1) para capturar os efeitos das vantagens competitivas advindas dos ganhos de escala, além da maior possibilidade de financiamento e capacidade de correr riscos, o tamanho da firma foi representado pelo logaritmo do número de empregados (PO), proxy utilizada em diversos trabalhos; (2) a produtividade da firma corresponde no modelo ao logaritmo do valor de transformação industrial sobre o número de empregados; (3) uma vez que as bases não fornecem dados explícitos sobre investimento em inovação ${ }^{3}$, optou-se por utilizar o logaritmo da escolaridade média dos funcionários como um indicador do nível de sofisticação do processo produtivo e o grau de utilização de capital; (4) a idade da firma entra no modelo como o logaritmo do tempo de trabalho do funcionário mais antigo; e (5) dummies para os setores (CNAE a dois dígitos).

A amostra aqui é composta apenas por empresas que não exportaram em pelo menos um dos anos entre 1996 e 2003, uma vez que o objetivo é justamente analisar a probabilidade de empresas domésticas se tornarem exportadoras. O matching é feito ano a ano e o procedimento procura casar empresas que obtiveram financiamento (e não exportaram) no ano em questão com aquelas que não contaram com o apoio do BNDES (e também não exportaram). A formação dos quatro grupos segue também o critério já exposto: grupos 3 e 2 são formados pelas empresas pareadas que obtiveram e não obtiveram financiamento, respectivamente. Portanto, para cada ano do período analisado, o procedimento forma os grupos de empresas.

\footnotetext{
3 A Pesquisa de Inovação Tecnológica (Pintec) do IBGE não foi utilizada na construção do banco de dados porque a pesquisa não é censitária para firmas com menos de 500 empregados.
} 
A comparação é feita entre os grupos 2 e 3 e observa-se para tanto o percentual de empresas de cada grupo que começou atividades de exportação no período de três anos subsequente ao ano do pareamento. Vale ressaltar que, antes da comparação final, as empresas que originalmente pertenciam ao grupo 2 (constituído por firmas que não obtiveram financiamento no ano $j$ ), mas que receberam algum financiamento do BNDES no período compreendido entre os anos $j+1$ e $j+3$, são excluídas do grupo 2. Assim, a comparação é feita entre empresas que receberam financiamento no ano $j$ (podendo ter recebido também em outros anos) e as empresas que não receberam financiamento em nenhum dos anos analisados. Utiliza-se, então, o teste chi-quadrado para comparar os percentuais de empresas que iniciaram atividades de exportação em cada grupo.

\section{ANÁLISE DOS RESULTADOS}

Este trabalho estuda o comportamento das firmas no mercado internacional entre os anos 1996 e 2003. Neste período, a base exportadora industrial brasileira cresceu aproximadamente $17 \%$ e, como exposto na tabela 1 , a média anual de empresas estreantes ficou um pouco acima de 15\% entre 96 e 2003, enquanto 14\% das firmas que exportaram em determinado ano não exportaram no ano seguinte.

Especificamente quanto à avaliação da capacidade dos financiamentos do BNDES aumentarem a probabilidade da empresa iniciar suas atividades exportadoras, os resultados parecem ser incontentáveis. Como mencionado na metodologia, o PSM proposto procura casar empresas domésticas que receberam algum tipo de apoio do BNDES com empresas domésticas que não receberam apoio do banco. Este pareamento gera os grupos 2 e 3, compostos, respectivamente, por empresas que não contaram com nenhum tipo de financiamento do BNDES e que receberam financiamento de alguma modalidade do banco.

TABELA 1 - BASE EXPORTADORA BRASILEIRA 1996-2003

\begin{tabular}{lrrrrrr}
\hline \multicolumn{1}{c}{ Ano } & \multicolumn{1}{c}{ Total } & Estreantes & Desistentes* & Estreantes (\%) & Desistentes (\%) \\
\hline 1996 & 6228 & 955 & 1042 & 15,33 & 16,73 \\
1997 & 6221 & 1035 & 856 & 16,64 & 13,76 \\
1998 & 6303 & 938 & 869 & 14,88 & 13,79 \\
1999 & 6565 & 1131 & 912 & 17,23 & 13,89 \\
2000 & 6776 & 1123 & 852 & 16,57 & 12,57 \\
2001 & 7058 & 1134 & 1038 & 16,07 & 14,71 \\
2002 & 7046 & 1026 & 903 & 14,56 & 12,82 \\
2003 & 7287 & 1144 & - & 15,7 & - \\
\hline Média & 6685,5 & 1060,8 & 924,6 & 15,87 & 14,04 \\
\hline
\end{tabular}

FONTE: Elaboração do autor e do IPEA.

NOTA: *Desistentes do ano $n$ são aquelas que exportaram em $n$, mas não exportaram no ano $(n+1)$. 
A tabela 2 traz o percentual de empresas que iniciaram atividades de exportação em cada um dos grupos no intervalo de três anos subsequentes ao pareamento. Nesta comparação, verifica-se que em torno de $20 \%$ das empresas que receberam algum financiamento do BNDES (grupo 3) passam a exportar num prazo máximo de três anos, enquanto aproximadamente $13 \%$ das empresas que não receberam nenhum tipo de financiamento iniciam atividades de exportação no mesmo período. Vale notar que estes percentuais não se alteram significativamente de ano para ano. No caso do grupo 3, com exceção de 2003, o percentual fica sempre entre 19 e 23\%, com média de 19,95\%. Para o grupo 2 , enquanto a média dos anos é de $13,15 \%$, o percentual nunca ultrapassa os $15 \%$.

Finalmente, em termos de comparação entre os grupos, é interessante notar que, apesar da metodologia criar grupos de controle e tratamento similares em aspectos de relevância para a atividade exportadora, a diferença entre os percentuais de cada grupo fica na casa dos 6 e $7 \%$ em seis dos oito anos analisados.

Todos os resultados do teste chi-quadrado, realizado ano a ano, rejeitam a hipótese de que as distribuições dos grupos entre as categorias "ingressaram" e "não ingressaram" são iguais, apesar da diferença entre os percentuais não ser tão expressiva em alguns anos, como é o caso de 2003. O que explica a força do resultado é o grande número de observações: em sete dos oito anos analisados, cada grupo é composto por mais de mil empresas.

TABELA 2 - PERCENTUAL DE INGRESSO NO MERCADO INTERNACIONAL

\begin{tabular}{|c|c|c|c|c|c|c|}
\hline Ano & Grupos & Não ingressou (\%) & Ingressou (\%) & Total & Núm. de observ. & Chi-quadrado \\
\hline \multirow[t]{2}{*}{1996} & 2 & 86,4 & 13,6 & 100 & 1164 & $<0,0001$ \\
\hline & 3 & 76,5 & 23,5 & 100 & 1172 & \\
\hline \multirow[t]{2}{*}{1997} & 2 & 85,0 & 15,0 & 100 & 1224 & $<0,0001$ \\
\hline & 3 & 78,0 & 22,0 & 100 & 1232 & \\
\hline \multirow[t]{2}{*}{1998} & 2 & 85,3 & 14,7 & 100 & 1089 & 0,0001 \\
\hline & 3 & 79,0 & 21,0 & 100 & 1097 & \\
\hline \multirow[t]{2}{*}{1999} & 2 & 86,0 & 14,0 & 100 & 735 & 0,0007 \\
\hline & 3 & 79,3 & 20,7 & 100 & 739 & \\
\hline \multirow[t]{2}{*}{2000} & 2 & 87,4 & 12,6 & 100 & 1059 & $<0,0001$ \\
\hline & 3 & 80,3 & 19,7 & 100 & 1070 & \\
\hline \multirow[t]{2}{*}{2001} & 2 & 86,8 & 13,2 & 100 & 1196 & $<0,0001$ \\
\hline & 3 & 79,5 & 20,5 & 100 & 1206 & \\
\hline \multirow[t]{2}{*}{2002} & 2 & 88,1 & 11,9 & 100 & 1324 & $<0,0001$ \\
\hline & 3 & 80,9 & 19,1 & 100 & 1328 & \\
\hline \multirow[t]{2}{*}{2003} & 2 & 89,9 & 10,2 & 100 & 1507 & 0,0124 \\
\hline & 3 & 86,9 & 13,1 & 100 & 1507 & \\
\hline
\end{tabular}

FONTE: Elaboração do autor e do IPEA.

\section{CONSIDERAÇÕES FINAIS}

Um aspecto do trabalho que pode ser entendido, à primeira vista, como uma limitação importante diz respeito ao fato das empresas que apresentam características únicas 
não encontrarem similares no pareamento realizado pelo método e, consequentemente, não comporem o grupo de tratamento. Assim, a metodologia poderia excluir da análise empresas importantes da lista de clientes do banco. Esta é uma maneira, senão incorreta, simplificada de analisar a questão. Os resultados finais do trabalho advêm de uma análise estatística que, identificando um impacto positivo dos financiamentos do banco, como é o caso, equivaleria à seguinte afirmação: diante de um número suficientemente grande de empresas que compõem os grupos de tratamento e controle e diante da diferença de desempenho das empresas destes dois grupos, pode-se afirmar que os financiamentos do BNDES geram impactos positivos na variável analisada. Vale dizer que este é um resultado estatístico e não individual, válido para todas as empresas que são financiadas pelo banco, estando ou não no grupo de tratamento. Note que o fato de uma empresa específica estar ou não compondo o grupo de tratamento altera apenas marginalmente os resultados.

Quanto ao impacto dos financiamentos do BNDES na probabilidade das empresas ingressarem no mercado internacional, os resultados são extremamente fortes: para todos os anos analisados, a probabilidade de uma empresa financiada pelo BNDES iniciar atividade de exportação em um dos três anos subsequentes é estatisticamente significativo e maior que a probabilidade das empresas não financiadas ingressarem neste mercado, a 5\% de significância.

Portanto, a partir da metodologia empregada, pode-se afirmar que os financiamentos do banco aumentaram inequivocamente a probabilidade das empresas ingressarem no mercado internacional, mesmo que de forma indireta. 


\section{REFERÊNCIAS}

ARAÚJO, B.C.P.O. Potencial das firmas industriais brasileiras e a dimensão tecnológica. In: DE NEGRI, J.; ARAÚJO, B.C.P. As empresas brasileiras e o comércio internacional. Brasília: IPEA, 2006.

ARAÚJO, B.C.P.; DE NEGRI, J. As empresas brasileiras e o comércio internacional. In: DE NEGRI, J.; ARAÚJO, B.C.P. As empresas brasileiras e o comércio internacional. Brasília: IPEA, 2006.

DE NEGRI, J.A. Desempenho exportador das firmas industriais no Brasil: a influência da eficiência de escala e dos rendimentos de escala. Brasília: Ipea. 2003. Texto para Discussão, n.997.

MARKWALD, R.; PUGA, F. Focando a política de promoção de exportações. In: PINHEIRO, A.C.; MARKWALD, R.; e PEREIRA, L.V. O Desafio das Exportações. Rio de Janeiro: Banco Nacional do Desenvolvimento Econômico e Social, p. 97-154, 2002.

PARSONS, L.S. Reducing bias in a propensity store matched-pair simple using greedy matching techniques. Proceedings of the twenty-sixth annual users group international conference, SAS, 2001.

SOUZA; F.; OTTAVIANO, G. O Efeito do BNDES na Produtividade das Empresas. In: DE NEGRI, J.; KUBOTA, L.C. Políticas de Incentivo à Inovação Tecnológica. Brasília: IPEA, 2008. 